\title{
Towards sustainable urban development: the social acceptability of high-rise buildings in a Ghanaian city
}

\author{
Felix S. K. Agyemang - Elisabete Silva • Prince Aboagye Anokye
}

Published online: 13 December 2017

(C) The Author(s) 2017. This article is an open access publication

\begin{abstract}
Over the years, many city managers, policy makers and academics alike have turned to high-rise buildings as pathway to sustainable urban development. However, the sustainability of such types of development in various geographical contexts, especially in sub-Saharan Africa, is a subject less explored. Amidst the promotion of high-rise development in a rapidly urbanizing metropolis in Ghana, Kumasi, the research empirically examined the social acceptability of high-rise residential facilities and the institutional capacity for their effective management. By conducting face-to-face interviews with sampled households, and critical public service providers in the metropolis, the study uncovered that, contrary to the evidence from many Asian cities, there is generally low social acceptability of high-rise developments, and a weak institutional capacity for effective service delivery. The research concludes that, whilst it is tempting to embrace high-rise buildings as sustainable development pathway, it is crucial they are pursued with much circumspection. In addition to their design being tailored to the local
\end{abstract}

F. S. K. Agyemang $(\varangle) \cdot$ E. Silva

Lab of Interdisciplinary Spatial Analysis, Department of Land Economy, University of Cambridge, Cambridge, UK

e-mail: fska2@cam.ac.uk

P. A. Anokye

Department of Planning, Kwame Nkrumah University of

Science and Technology, Kumasi, Ghana needs of the people for whom they are built, the promotion of high-rise development should recognize the importance of effective service delivery, and general social acceptability.

Keywords High-rise development $\cdot$ Social acceptability · Sustainability · Institutional capacity · Ghana

\section{Introduction}

While urbanization is a global phenomenon, it has been particularly massive and rapid in developing countries over the past few decades (UN 2014; Pacione 2009). Indeed, Africa and Asia are projected to absorb a whopping nine in every ten additional urban dwellers expected in 2050. This, in spatial terms, reflects on the one part, a change in status of settlements from rural to urban, and growth of existing urban settlements on the other. These, in many instances, trigger an evolution in urban spatial structure, for instance, the case of Accra City-Region (Agyemang et al. 2017). This evolution normally occurs at the expense of surrounding environment in terms of land cover. Stemming from these trends, the quest for sustainable urban development is fast gaining patronage at the global level (Yuen et al. 2006). In addition to occupying critical policy attention, many city managers have in diverse ways, largely 
through the promotion of high-rise developments, pursued compact urban form (Wong 2010; Healy and Birrell 2006).

However, despite the seemingly compelling reasons for the adoption of high-rise buildings as pathway to sustainable development, a number of concerns, many of whom borders on issues of safety and energy efficiency, have reverberated globally. Indeed, recent incidents, including the Grenfell Tower tragedy,- - a huge fire that gutted the tower block in West London and claimed about 80 lives (Scott, 2017)—-seems to have re-ignited the discourse about the safety of tall buildings. Whilst it may be understandable that the discussions are dominated by safety and energy efficiency issues, it is equally important that other fundamental and critical issues, such as, the social acceptability of high-rise buildings is accorded research prominence. For instance, is the pursuit of high-rise developments in various geographical context backed by social support, or is it a conception of technical rationality that is isolated from social realism? Answers to these questions are vital, as they are at the core of whether high-rise developments should be pursued in the first place.

It is also noted that, while, generally, there is limited knowledge on social acceptability of high-rise buildings, the problem is quite pronounced within the context of sub-Saharan Africa. Thus, a grey area that requires much light, is whether people in various cities in the sub-region prefer high-rise living. Tightly linked to this, is the need for an examination of the capacity of institutions charged with the delivery of essential services in high-rise facilities. Again, the need for research in this area cannot be overemphasized, particularly, when juxtaposed with the necessity for a well-grounded policy direction on high-rise buildings.

As a contribution to filling the aforementioned knowledge deficit, and informing policy direction in parts of Africa, this research examines the sociocultural acceptability of high-rise buildings, and the institutional capacity for efficient service delivery. Pursuant to this, empirical data is drawn from Kumasi metropolis, a rapidly urbanizing city in Ghana. Stemming from its high pace of expansion and sprawl (Acheampong et al. 2017; Cobbinah and Amoako 2012), the local planning authorities of Kumasi metropolis have turned to the promotion of high-rise buildings, especially in the Central Business District (CBD).

The paper is organized into six sections. The next section, drawing from literature, presents an overview of vertical development at the global scene. This is followed a discussion of the methodology employed. The "Results" section then takes off, with the first part exploring households' opinions and preferences for high-rise living, while the second dissects the capacity of key service providers. In the "Discussion" section, the results are compared with those from other studies around the world, and policy implications are inferred. A conclusion is drawn in the last section.

\section{Vertical developments: an overview}

\section{Historical context of vertical development}

The definition of high-rise development is geographically sensitive, and as a result, far from absolute (Buchanan 2008). For instance, whilst 30 storeys are generally considered tall in London, they are viewed as average in New York City (Buchanan 2008). In accounting for the historical evolution of high-rise developments, it is important to place into context the significant role of elevators. The invention of high speed elevator during the period of industrial revolution catapulted the proliferation of high-rise buildings (Ali and Moon 2007). Vertical developments became a prominent feature of many cities in the twentieth century. Early conceptual development by Le Corbusier, and later by Wright and Soleri made a significant contribution to the development of highrise buildings in the early decades through to the middle part of the twentieth century (Wong 2004; Yuen et al. 2006). The latter period of the century saw major advancement in construction technology, which together with booming population, urbanisation, and land scarcity, especially, in Asia, accelerated the development of high-rise buildings (Lee et al. 2011; Mahgoub and Abbara 2011). During the same time in Australia, growth in slum population had been a contributing factor (Costello 2005).

By the 1960s, high-rise developments had become popular in the US, Asia, Europe and Australia (Yuen 2005). Afterwards, in the 1970s, many of the criticisms of vertical development emerged (Yuen et al. 2006). Most of the criticism were centred on the social 
effects of high-rise living (Costello 2005; Gifford 2007). The pace of high-rise development slowed down in many cities in the 1970s and few decades afterwards. However, the quest for compact settlements, and increased awareness for sustainable development (Gonçalves 2004) heightened touristic attraction for vertical developments, rekindled highrise developments in many cities in the 1980s and 1990s.

The state of vertical development in the twentyfirst century

Contrary to the predictions of many researchers after the bombing of the World Trade Centre in September 11, 2001, cities have continued to grow vertically (Parker 2014). Indeed, in contemporary times, many city authorities have embraced high-rise buildings as tools for pursuing urban compactness, sustainability. For instance, in response to massive urban population growth, urbanization, scarcity of land, the city authorities of Singapore and China have promoted tall buildings (Chen et al. 2012; Choi et al. 2012). The economic viability of tall buildings, as well their perceived manifestation of economic power, has catalysed vertical development in Australia and the gulf region in the twenty-first century (Costello 2005; Short 2007).

In Europe, the quest for compact cities, shortage of housing, and planning policies, especially in the UK, have catapulted high-rise development in the continent (Tavernor 2007; Evans and Unsworth, 2011). The city of London, for instance, continues to grow taller, as the permitting, and development of high-rise buildings has been on the rise (Tavernor 2007).

The pull and push factors of high-rise buildings in the contemporary global arena

Today, several factors attract and repel vertical development in the global arena. Popular in Europe, especially in the UK, is the perceived impediment on heritage (Short 2007; Tavernor 2007). Again, in many parts of the UK, tall buildings have been neglected, and command low public status (Turkington et al. 2004). Vertical developments have also created environmental and urban management problems, such as, congestion, pollution, increased energy consumption and waste creation (Feng and Xingkuan 2011; Wener and Comalt 2006). Hamilton et al. (2017) contends that high-rise buildings, relative to regular ones, consume more gas.

High-rise buildings are also known to present enormous challenges to, the health of some of their occupants, and the providers of prehospital care (Mao and Ong 2016). Indeed, Drennan et al. (2016) found that, in Toronto, patients who occupied the upper floors of tall buildings were more susceptible to not surviving cardiac arrest that occurs out of hospital.

Socially, factors encompassing, diminishing communal spirit, creation of mental and psychological defects, which stem from isolation of occupants from ground space, are among the repellents of high-rise buildings (Wong 2004; Cho and Lee 2009). Also, high-rise living is seen by many households with children as less safe (Costello 2005). Indeed, many of the high-rise council housing, which were constructed in the 1960s in the UK, have been socially unpopular, and are treated as market residue (Turkington et al. 2004; Jones and Murie 2006). Moreover, rescue operations during emergencies are also difficult in tall buildings (Liu et al. 2012). Firefighting operations in tall buildings, particularly from seventh floors or higher, tend to be problematic (Isman 2017). The Grenfell Tower tragedy, a huge fire that gutted the tower block in West London and claimed about 80 lives (Scott 2017) attests this.

Notwithstanding these forces, cities have grown taller. The aesthetic view offered to many has been a major accelerator of high-rise buildings (Wong 2004). Similarly, many city authorities have embraced the iconic view of tall buildings (Tavernor 2007). Indeed, a study in Singapore has shown that owing to special scenic view, people pay extra price to occupy higher floors (Yuen et al. 2006).

Other critical factors, which have propelled the continued development of high-rise buildings, include: scarcity and high cost of land coupled with growing population (Liu et al. 2012); quest for compact cities, and sustainable development by many planners and city authorities (Gonçalves 2004; Lee et al. 2011); maximization of profit by developers (Short 2007); and national pride and prestige (Mahgoub and Abbara 2011). Moreover, there has been the argument that high-rise buildings and high densities are more efficient in terms of energy consumption. See, for instance, Resch et al. (2016). In a nutshell, despite the push factors, there are plethora of forces 
which have made high-rise developments indispensable in urban planning and management hence the continuous growth in height of many cities.

\section{Methodology}

The case study in context

The study is situated in the Central Business District (CBD) of Kumasi metropolitan area, located within the Ashanti Region of Ghana, as presented in Fig. 1. The metropolitan area, which extends over approximately $212 \mathrm{~km}^{2}$ of land, emerged as the most populous administrative district unit in Ghana during the last census in 2010. With an initial population of about 1.2 million at the beginning of the twenty-first century, the metropolis gained an additional 800,000 people during the period between 2000 and 2010, hence increased its population to about 2 million. (Ghana
Statistical Service 2013). In the process, the metropolis grew at $5.7 \%$ annually, one of the highest annual growth rates recorded in the country.

\section{Methods}

The research employed qualitative approach by drawing on empirical data collected from 50 heads of households, a number which represented a saturation in the responses. There was, first, a reconnaissance survey of the CBD. In the sampling process, using major roads as boundaries, the $\mathrm{CBD}$ was demarcated into 10 clusters. A number of households, ranging from 3 to 7 , were selected from each cluster. Not more than one household was selected for a house, meaning the 50 were sampled from an equal number of houses. The selection of houses preceded the sampling of the households. The housing density in the various clusters underpinned the determination of the exact number of houses that were selected from each.

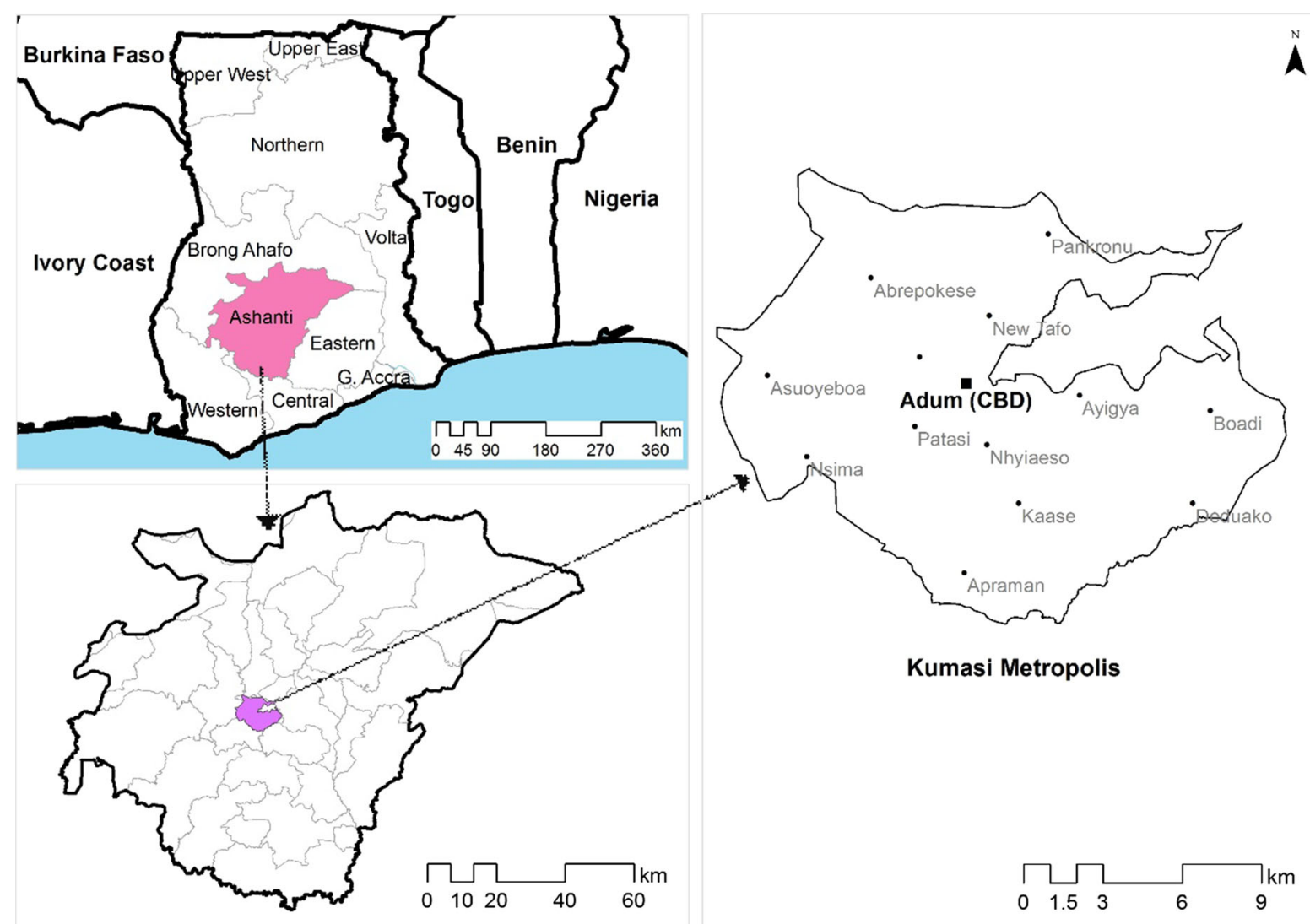

Fig. 1 Contextual location of Kumasi metropolis CBD Source: Authors, based on spatial data from TCPD, 2015 
Subsequently, households were randomly sampled, and interviewed. Having administered 40 questionnaires, the width of the study stagnated as no new codes/responses emerged. Upon administering additional 10 questionnaires, the stagnation in the diversity of responses was confirmed. Using the concept of saturation in qualitative research (Fusch and Ness 2015; Mason 2010), the study settled on the 50 as a representative sample of the study population. Even though the study is generally qualitative, statistical tests such as Chi square and spearman correlation have been performed where appropriate.

In examining the institutional capacity to deliver effective services in high-rise buildings, three critical institutions: the Ghana Fire Service, Ghana Water Company Limited, and the National Disaster Management Organisation were interviewed. The Town and Country Planning Department (TCPD) of the Kumasi Metropolitan Assembly (KMA) was also interviewed to understand the planning and the policy context of high-rise buildings. The interviews were conducted through face-to-face technique with interview guides and semi-structured questionnaires.

\section{Results}

The results have been presented and discussed under three major sections: social acceptability, institutional capacity and interaction between the two. In examining the social acceptability, residents' general opinions and preferences for high-rise developments have been analysed taking into cognisance, variables such as gender, age, housing typology, and floor of occupation. However, prior to that, the context and characteristics of high-rise developments in the metropolis, are first presented.

High-rise buildings in the CBD of Kumasi

Metropolis: context and characteristics

Majority of dwellings in Kumasi metropolis are compound houses, a traditional housing typology, which is particularly dominant (53\% of all dwelling unit) in the Ashanti Region (Kumasi Metropolitan Assembly 2010). Data on high-rise buildings in Kumasi metropolis is very sketchy. That notwithstanding, interviews with the TCPD revealed that, prior to the last decade of the twentieth century, buildings in the CBD were predominantly 2 storeys. Upon sensing the rapidity of the city's expansion and the need to accommodate more households and businesses in the CBD, the TCPD, which is responsible for the preparation of plans and issuance of development permit, introduced a new building height standard of 4 storeys minimum. The CBD-centric minimum height specification was instituted in 1990. The spatial context of the expansion of the city, which prompted the city authorities' reliance on high-rise buildings as pathway to sustainable development, is depicted in Fig. 2. The figure, which is an extraction from (Acheampong et al. 2017); a classification of Landsat images for Greater Kumasi Sub-region, shows the historical built-up and non-built-up areas of the metropolis.

Whilst there is no comprehensive data on the exact height of buildings, our interview with the TCPD revealed that the number of storeys ranged from 1 to 7 , with 3 as the average. This was corroborated by close inspection of randomly selected streets, and the experiences of some of the authors who have lived and worked in the city. Most of the buildings above 3 storeys are located within the CBD, and have multipurpose uses, largely, commercial-residential, and residential-administrative. Majority of the facilities in the CBD (about 85\%) are privately owned, while public and joint ownership (public and private) account for about 10 and 5\% respectively. More than half of the private facilities are owned by individuals, the very rich in the society. However, their clients, people who rent and occupy the residential high-rise dwellings are largely low and middle-income earners who normally cannot afford detached houses.

Residents' general opinions on high-rise developments

Majority $(80 \%)$ of residents hold positive opinion about the general concept of vertical development, whilst $10 \%$ think the idea is a bad one. Quite a significant proportion of the respondents, another $10 \%$, are indifferent regarding their opinion on vertical developments. Is there a relationship between the general opinion of residents and variables, such as, age, gender, and educational level attained? A bivariate correlation analysis shows that there is no statistically significant relationship between residents' opinions about high-rise buildings, and, gender 


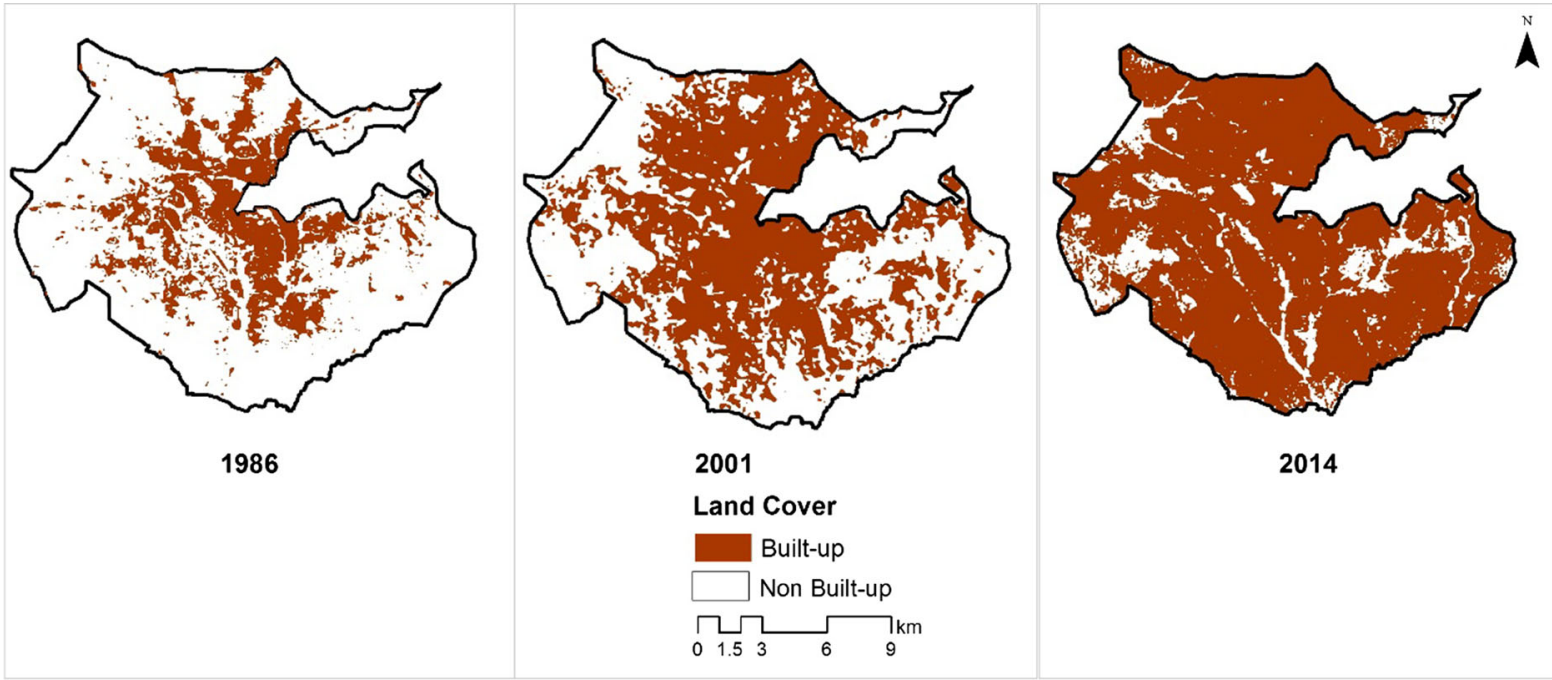

Fig. 2 Historical built-up extent of Kumasi Metropolis Source: Extracted and processed from Acheampong et al. (2017)

$(\mathrm{r}=.079, p>0.05)$, age $(\mathrm{r}=-.12, p>0.05)$, and educational level $(\rho=-.09, p>0.05)$.

\section{Reasons behind residents' opinion on high-rise buildings}

Several factors account for residents' opinion about high-rise buildings, and these are presented in Table 1. According to over $40 \%$ of respondents, vertical developments ensure effective utilization of space, while close to one-fifth (18\%) view such developments as risky, especially during emergency cases. About $10 \%$ of residents believe vertical developments are multi-functional, and presents the opportunity for integrating multiple uses in one place. Aesthetics, which features prominently in literature (Wong 2004; Tavernor 2007) as a propelling factor of vertical development, is cited by $6 \%$ of the respondents. Quite related, $8 \%$ of residents attribute their opinion to nice aerial view offered by such developments. Regarding health, whereas $2 \%$ of residents think of the energy required for climbing stairs as a good form exercise, a similar proportion interprets such requirements as tiring and bad for their health.
Table 1 Factors behind residents' opinion about vertical development Source: Field survey, February 2013

\begin{tabular}{llrr}
\hline Type of opinion & Reasons & Number & Percentage \\
\hline Positive & Efficient use of space & 22 & 44 \\
& Good for health (form of exercise) & 1 & 2 \\
& Promotion of compact spatial form & 1 & 2 \\
& Multi-functionality & 5 & 10 \\
& Aesthetics & 3 & 6 \\
& Nice aerial view & 4 & 8 \\
& Solution to problems of accommodation shortage & 3 & 6 \\
& Prestige & 1 & 2 \\
Sub-total & & 40 & 80 \\
Negative & Risky during emergency problems & 9 & 18 \\
& Bad for health (requires more energy) & 1 & 2 \\
Sub-total & & 10 & 20 \\
Total & & 50 & 100
\end{tabular}


Residents' preferences for living on higher floors

Notwithstanding that majority of residents hold positive opinion about vertical developments, their preference for occupying higher floors ${ }^{1}$ differ. Indeed, slightly more than half of the sampled respondents have no preference for living on any floor higher than the ones they occupy. It appears females are, relatively, reluctant to high-rise living. While more than half $(52 \%)$ of females have no preference for living on higher floors, the opposite is true for males (52\% have preference for higher floors).

More than half of residents who prefer to live on higher floors attribute their preference to the nice aerial view that such heights offer. Other influential factors are presented in Table 2. About $12 \%$ of the respondents predicate their preference on economic grounds. According to this segment of the sampled population, rents for higher floors are relatively cheaper, hence it is economical to occupy them. Another $12 \%$ of residents do not object to occupying higher floors, simply, as a result of being indifferent to living on ground or higher floors. The preoccupation of these residents is more about access to accommodation rather than height of living.

\section{Residents' height limit preferences}

The study finds significant variations in the height limit preference of residents. While the third floor emerge as the average limit, the seventh floor is highest height preference. Further disaggregation of data uncovers that the highest floor preference varies among gender. Whereas, on the average, males expressed four floors as their limit, females had no preference for living on floors above two. In contrast, the correlation between height limit preference, and the educational level of residents is weak, but nonstatistically significant $(\mathrm{r}=.27, p>0.05)$. Also, a negative, weak, but statistically insignificant correlation is expressed between height limit preference and age of residents $(\mathrm{r}=-.2, p>0.05)$.

By examining residents' floor of occupation, and their preference for higher floors, an interesting

\footnotetext{
1 The usage of higher floor is relative to respondent's floor at the time of being interviewed. For example, higher floor of an occupant of first foor is any floor above 1 , whereas that of third floor occupant is any floor above 3 .
}

relationship is uncovered. First, the results of a cross tabulation between the two are presented in Fig. 3. In conducting further test, residents' floor of occupation is dichotomized into two categories: above second floor, on one side, and, second floor and below on the other. A Chi square test $\left(x^{2}\right)$ reveals a significant association between residents' floor of occupation, and their preference for higher floor living, $x^{2}(1)=$ $15.8, p<0.05, P h i=0.561$. These values indicate that, the association between the two variables is large and statistically significant. The size effect has also been interpreted in relation to odds ratio, which shows that residents who live above second floor have 13 times the odds of not preferring a higher floor, relative to occupants of second floor, and below. This is striking in the sense that these residents non-preference could have been shaped by experiences, something delved deeper in the next sub-heading.

Aside the fact that many residents who hold preference for high-rise living are unwilling to live beyond third floors, majority have no preference at all. A number of reasons, including, less safety, lack of elevators, irregular flow of water, and other inconveniences, have been attributed to the non-preference. Among these, absence of functional elevators in highrise buildings is commonly cited by close to half (48\%) of residents. According to these residents, much energy is required for conducting daily activities. Close to $80 \%$ of respondents who expressed such frustration also lamented on the erratic nature in the flow of water on higher floors. According to these resident, one is compelled to manually transport water from ground to upper floors, a daily task which could be very stressing.

Approximately one-third of residents also attribute their non-preference to safety issues. Safety issues that have been raised include, uncertainty in timely response in case of emergency; and threats of children falling over. Female residents in the CBD were, particularly, concerned with the safety of high-rise apartment than males, as the former constitutes approximately three-quarters of residents who attributes non-preference to safety issues. Again, more than $60 \%$ of residents who find high-rise buildings as less safe, live in apartments, which are also tall buildings, particularly in the context of Kumasi metropolis. The assessments were, therefore, largely 
Table 2 Reasons behind residents' preference for higher floor living Source: Field survey, 2013

\begin{tabular}{lcc}
\hline Reasons & Number & Percentage \\
\hline Nice aerial view & 15 & 62.5 \\
Cheaper rent & 3 & 12.5 \\
Indifference (between higher floors and ground living) & 3 & 12.5 \\
Privacy & 2 & 8.3 \\
Good for Health & 1 & 4.2 \\
Total & 24 & 100 \\
\hline
\end{tabular}

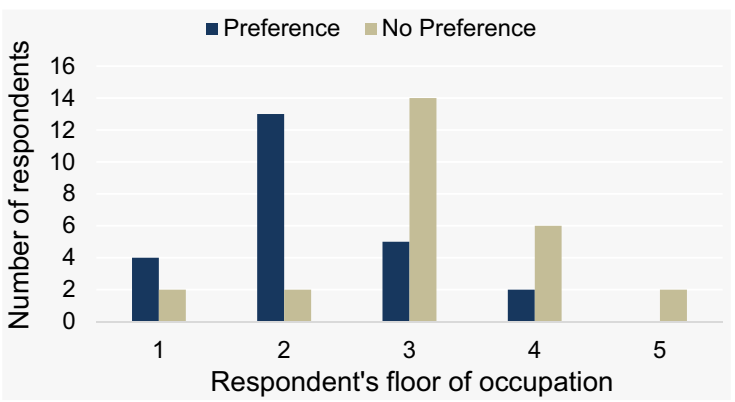

Fig. 3 Residents preference for higher floors by their floor of occupation Source: Field survey, 2013

based on the experiences that the residents have encountered with tall buildings.

Again, close to $20 \%$ of residents who have no preference for living in high-rise buildings pointed to other inconveniences with high-rise living. Majority of these respondents outline the challenges confronted with the preparation of their highly preferred local dish, Fufu. the orthodox preparation this food, which is the traditional food of the region, requires much vertical space. The design of most high-rise buildings in the metropolis, makes them less suitable for the preparation of this food. Besides, the owners of highrise buildings discourage, as much as possible, the pounding of fufu in upper floors. This, largely, stems from the debilitating impact that the pounding process could have on the structure of the building. Cracks are generated, and maintenance cost of the building increases limits.

Capacity of institutions in relation to high-rise development

The social acceptability of high-rise buildings is highly influenced by the consumption of certain basic and critical services provided by institutions. Whilst some of the services affect day to day living, for instance, water provision, others are more occasional. Example of the latter is disaster response. The capacity of institutions responsible for the provision of some of the critical services is therefore crucial in examining the social acceptability of high-rise buildings.

\section{Ghana Fire Service (GFS)}

As highlighted in literature, the difficulty and complexity of carrying out emergency operations (such as fire rescue mission), limits the attractiveness of vertical development (Liu et al. 2012). The GFS disclosed its maximum height capacity as, approximately, six floors. This posits severe risk and safety questions to owners and users of high-rise facilities that exceed six storeys. Even within the capacity of six floors, the services of the GFS are fraught with inefficiencies. The GFS confronts acute inadequacies in logistics and skilled personnel. Indeed, a senior officer of the institution rated the logistical and human resource capacity of the institution as average. The officer, who granted the authors the interview, further stated:

... The nature of services we render demand that logistics be provided frequently yet they do not come as often as they should. ... The human resource capacity is average because the length of training at the Fire Service Training School is shortened so all prerequisite skills are not fully acquired. Again, no in-service training with respect to high rise facilities is given to personnel

\section{Ghana Water Company Limited (GWCL)}

It is apparent, from the household survey, that the supply of water beyond second floors is irregular. An interview with the Public Relations Officer (P.R.O.) of 
the GWCL, revealed that, the pressure of water supplied by GWCL is 'one bar', which cannot serve beyond 10 meters height (approximately, two floors). The GWCL also appears to have challenges with highrise facilities, owing to their occupation by multiple tenants. The P.R.O. further stated:

In houses which are made up of multiple tenants it is difficult to disconnect the water supply if other tenants do not pay because it will affect others who pay. Billing is also difficult in high rise buildings as most developers design their plumbing system together to use one meter so that a whole flat receives one bill and sharing becomes difficult which also affects the rate of payment.

Thus, the institution has problems with generating revenues from high-rise buildings that mostly accommodate multiple tenants. When asked whether there were plans to extend the vertical reach of services provided by the corporation, the PRO responded:

No. Currently we have problems with even getting water to supply to the majority of people on ground floors, and that is our greatest priority. We do not have the capacity in terms of equipment, and are not ready to provide services to high-rise buildings.

\section{National Disaster Management Organisation (NADMO)}

The capacity of NADMO in relation to high-rise rescue operations is not different from that of GWCL. Aside logistical challenges, the organization is faced with inadequate skilled personnel. The metropolitan coordinator of NADMO articulated:

We do not have adequate logistics and machinery for reaching higher floors... The workers available are low skilled to handle high floor operations. There has been no training in a long while especially with the new employees as a result of inadequate funds.

In summary, all the three critical institutions whose services are so essential to the safety and convenience of high-rise living lacked the capacity to deliver efficient services. Similarly, reasons for the poor service delivery largely owing to inadequate logistics, machinery and skilled personnel were common to the institutions. These boils down to insufficient financial resources either in the form of the GWCL not being able to generate enough revenue from users or the GFS and NADMO not receiving enough funds from central government.

\section{Discussion}

Despite that majority of residents have good opinion about the concept of high-rise developments, many have no preference for occupying them. Majority of those who have preference for high-rise developments, are unwilling to dwell above 3 floors. With reference to gender, majority of females are not prepared to dwell beyond the second floor, whereas males have four floors as their limit. The absence of elevators, and safety issues are major factors that underline residents' non-preference for high-rise facilities. In addition, the design of majority of highrise buildings inhibit the ability of residents to prepare their highly preferred food, fufu, which also happens to the traditional food of not just the metropolis, but the region at large.

Thus, contrary to the findings of Yuen et al. (2006), which revealed that households in Singapore were more willing to live on higher floors, residents in Kumasi metropolis are generally repulsive to high-rise living. Indeed, in the case of Singapore, the abovementioned study highlighted the high value attached to high-rise living, where households, owing to attractions such as, nice aerial view, privacy, etc., found reason in paying extra for higher floors (above 30 storeys). In sharp contrast, more than half of the residents in Kumasi hold absolutely, no preference for high-rise living. Those who prefer high-rise living have an average height limit three floors. That mentioned, and like the study stated above, nice aerial view is one of the major driving forces behind the residents' preference for high-rise living.

The social unpopularity of high-rise developments in the metropolis is comparable to similar attitudes in the UK, for instance, see (Ipsos MORI 2016; Turkington et al. 2004; Jones and Murie 2006; Bramley et al. 2004). Moreover, as with the findings of Short (2007) and Tavernor (2007), which pointed to a conflict between high-rise buildings and cultural heritage in the UK, significant proportion of residents 
in Kumasi metropolis view high-rise living as an impediment their ability to prepare their traditional food. Thus, from the cases of Singapore, UK, and now Ghana, it can be inferred that social acceptability of high-rise living is culture sensitive.

Also, the study affirms the findings of (Ali and Moon 2007) pointed to the invention of high speed elevators as a major factor that has propelled the development of high-rise buildings. Similarly, majority of residents Kumasi metropolis attribute their nonpreference for high-rise living to the absence of elevators.

Nexus between weak institutional capacity and low social acceptability

From the results section, it appears that it is not just mere coincidence that there is low social acceptability, while the capacity of institutions responsible for the provision of critical services, is weak. First, the fact that people who resided above second floors had thirteen times odds of not preferring a higher floor living says a lot about the kind of experiences encountered with their high-rise living. Indeed, as pointed out in the results section, the people feel less safe in living on higher floors as a result of doubting the efficiency and effectiveness of emergency response units. This reflects the poor functionality of vital institutions such as NADMO and GFS. This is not in contravention to what we learn from literature, as, for instance, Liu et al. (2012) illuminates how difficulties in carrying out emergency operations limits the attractiveness of high-rise buildings. The interviews with the institutions attest that, the fears and doubts of the residents are not in a vacuum, as the two institutions mentioned above are severely challenged in terms of logistics and personnel, hence weakening their effectiveness.

Similarly, the unpleasant situation where occupants of higher floors have to, on regular basis, fetch water from ground floors reflects the poor services offered by the GWCL. This is much compounded by the absence of working elevators. Ensuring that high-rise buildings have functional elevators is the responsibility of institutions such as the Kumasi Metropolitan Assembly. Thus, like the case of irregular flow of water, institutional mal-functionality cannot be exonerated from the absence of working elevators.
Other results, such as, people finding higher floors as less comfortable for the preparation of their favourite meal, speaks volumes of how the design and development of high-rise buildings are detached from the context. Once again, this exposes some lapses in institutional functionality as the local assembly, represented by the TCPD and the Building Inspectorate Unit, have the mandate of ensuring that the design and development of tall buildings are tailored to address these contextual issues. In summary, overwhelming majority, if not all, of the centrifugal factors point to the mal-functionality of institutions. Thus, low institutional capacity occasioned by poor service delivery has negatively shaped people's preference for high-rise living, hence low social acceptability.

\section{Policy implications}

The results from the previous section show that, as with the sustainability of rapid urban expansion, there are as much issues with the sustainability of high-rise developments. Having uncovered a rather low social acceptability of such developments, and weak institutional capacity for effective service delivery, the research posits several policy implications for urban managers.

First, while the promotion of high-rise buildings is seen as a pathway to sustainable development by many urban managers, the sustainability of such type of development, particularly in Kumasi metropolis, is in itself questionable. The quest for wanting to curb urban sprawl should not be pursued blindly and hastily, as the likely abandonment of high-rise buildings, stemming from their low social acceptability might just be in sight. Within Kumasi, the sustainability of the increased minimum height requirements to four floors is much at risk, as there are deep seated social and institutional issues that must first be addressed. These boils down to galvanising social support for such types of development, stemming from which the following recommendations are made.

Pay attention to the functional capacity of providers of critical services: Stimulating the interest of households in high-rise facilities goes with making such types of development more user friendly. This starts with improving the delivery of key services such as water, functioning elevators and swift emergency response. The capacity of critical service institutions 
such as Ghana Water Company Ltd, Ghana Fire Service, and the National Disaster Management Organization require massive uplift. These institutions need much attention and support in the areas of logistic and personnel.

Improve the enforcement of development control regulations and specific building codes: The development of high-rise facilities should be given much prominence, especially with specifications, review, and enforcement of standards. This is crucial for winning the confidence of people regarding the safety of such developments. In enhancing safety, existing bye-laws and codes on high-rise developments should be enforced. However, preceding the enforcement of specific buildings, is the need to enforce development control regulations. This is particularly important considering that overwhelming majority of developments in the metropolis and the country are unauthorized. Whilst this is more symptomatic of developments undertaken by households, there is also evidence of big marker players, such as real estate developing companies, taking a similar route, see, for instance, Anokye et al. (2013). The problem here is, if majority of development are undertaken without going through the planning system, the enforcement of buildings codes becomes daunting, if not impossible.

The design of high-rise buildings should be a function of context: Closely linked to the point above, is the need for stakeholders to accord much attention to the context of the design and development of high-rise buildings. Since high-rise buildings are meant for people, their design and development should fit the context by of integrating the culture of the people. This is particularly important, as it is core to the acceptability of vertical developments. Thus, while it might be compelling to adopt the design of high-rise buildings of other regions, most importantly, they must be tailored to address the local needs of the people for whom they are built.

At the local level, planning authorities, in this instance, the Kumasi Metropolitan Assembly, should play a lead role in coordinating the efforts of institutions and technocrats connected with any of the stages of high-rise development. This will require detailed attention to the planning, design, construction, management and maintenance of high-rise buildings in the metropolis. For instance, whilst the TCPD ensures that only development applications with comprehensive provisions for safety and convenience of occupants are approved, it is imperative that the Building Inspectorate Unit commits resources to the inspection of all existing high-rise buildings for their operational conformity to safety standards.

Engage more with developers: Willing cooperation is key to the enforcement of rules, regulations, and codes. That said, the willingness to cooperate does not happen in a vacuum, but a product of processes that are more inclusive and engaging. In building cooperation from developers in relation to development codes, it is important that local authorities collaborate with, and engage them, even in the formulation of the codes. In other instances, it may best for local authorities to develop training programmes for developers in sensitizing the latter's consciousness them for user safety and convenience. Against the backdrop of city authorities seeing high-rise buildings as response to rapid urban expansion, such efforts by local authorities, more so the KMA, is vital.

\section{Conclusion}

The research has provided some empirical evidence on the social acceptability of high-rise buildings from a developing African city, using a qualitative case study approach. Having discovered, on the one hand, a rather low social acceptability, and, on the other, a weak institutional capacity for the provision of services to high-rise facilities, the research concludes that while there might be compelling evidence to adopt the path of high-rise development, there are as much issues with its sustainability, as with the rapid urban expansion that city managers seek to solve. Stemming from this, it is crucial that the pursuit of tall buildings is tailored with much circumspection; recognizing the importance of efficient delivery of certain services and improving the capacity of institutions in charge. Going forward, in strengthening the limited existing knowledge in the field, further studies on the subject matter are required in other parts of Africa, and this study, through its findings could serve as pointers. Possible threats to the sustainability of high-rise buildings in other contexts, owing to low social acceptability, weak institutional capacity, and other specific contextual issues, are some of the directions that this study points for future research 
Open Access This article is distributed under the terms of the Creative Commons Attribution 4.0 International License (http:// creativecommons.org/licenses/by/4.0/), which permits unrestricted use, distribution, and reproduction in any medium, provided you give appropriate credit to the original author(s) and the source, provide a link to the Creative Commons license, and indicate if changes were made.

\section{References}

Acheampong, R. A., Agyemang, F. S., \& Abdul-Fatawu, M. (2017). Quantifying the spatio-temporal patterns of settlement growth in a metropolitan region of Ghana. GeoJournal, 82(4), 823-840.

Agyemang, F. S., Amedzro, K. K., \& Silva, E. (2017). The emergence of city-regions and their implications for contemporary spatial governance: Evidence from Ghana. Cities, 71, 70-79. https://dx.doi.org/10.1016/j.cities.2017.07.009.

Ali, M. M., \& Moon, K. S. (2007). Structural developments in tall buildings: Current trends and future prospects. Architectural Science Review, 50(3), 205-223.

Anokye, P. A., Tanyeh, J. P., \& Agyemang, S. K. (2013). The emergence of gated communities in Ghana and their implications on urban planning and management. Developing Country Studies, 3(14), 40-46.

Bramley, G., Munro, M., \& Pawson, H. (2004). Key issues in housing: Housing markets and policies in 21st century Britain. Basingstoke: Palgrave Macmillan.

Buchanan, C. (2008). The economic impact of high density development and tall buildings in Central Business Districts: A Report for the British Property Federation.

Chen, L., et al. (2012). Sky view factor analysis of street canyons and its implications for daytime Intra-Urban Air temperature differentials in high-rise, high-density urban areas of Hong Kong: A GIS-based simulation approach. International Journal of Climatology, 32(1), 121-136.

Cho, S. H., \& Lee, T. K. (2009). A study on building sustainable communities in high-rise and high-density apartmentsFocused on living program. Building and Environment, 46(7), 1428-1435.

Choi, Y., Cho, S. H., \& Kim, J. T. (2012). Energy consumption characteristics of high-rise apartment buildings according to building shape and mixed-use development. Energy and Buildings, 46(1), 123-131.

Cobbinah, P. B., \& Amoako, C. (2012). Urban sprawl and the loss of Peri-Urban land in Kumasi, Ghana. International Journal of Social and Human Sciences, 6(1), 388-397.

Costello, L. (2005). From prisons to penthouses: The changing images of high-rise living in Melbourne. Housing Studies, 20(1), 49-62.

Drennan, I. R., Strum, R. P., Byers, A., Buick, J. E., Lin, S., Cheskes, S., et al. (2016). Out-of-hospital cardiac arrest in high-rise buildings: Delays to patient care and effect on survival. Canadian Medical Association Journal, 188(6), 413-419.

Evans, A., \& Unsworth, R. (2011). Housing densities and consumer choice. Urban Studies, 49(6), 1163-1177.

Feng, P., \& Xingkuan, W. (2011). Sustainable development of high-rise building. Procedia Engineering, 21(1), 943-947.
Fusch, P. I., \& Ness, L. R. (2015). Are we there yet? Data saturation in qualitative research. The Qualitative Report, 20(9), 1408-1416.

Ghana Statistical Service. (2013). Population and housing census: National analytical report. Accra: Ghana Statistical Service.

Gifford, R. (2007). The consequences of living in high-rise buildings. Architectural Science Review, 50(1), 1-16.

Gonçalves, J. C. S. (2004). The Tall building and the tall city: The discussion about urban sustainability. In PLEA (passive and low energy architecture), 21st conference on passive and low energy architecture. Eindhoven, Netherlands, 19-22 September 2004.

Hamilton, I., Evans, S., Steadman, P., Godoy-Shimizu, D., Donn, M., Shayesteh, H., et al. (2017). All the way to the top! The energy implications of building tall cities. Energy Procedia, 122, 493-498.

Healy, E., \& Birrell, R. (2006). Housing and community in the compact city. Melbourne: Australian Housing and Urban Research Institute.

Ipsos MORI. (2016). Londers support restrictions on new tall buildings. Ipsos MORI. Retrieved from https://www.ipsos. com/ipsosmori/en-uk/londoners-support-restrictions-newtall-buildings.

Isman, K. E. (2017). High rise buildings. In Standpipe systems for fire protection (pp. 235-257). Springer. https://doi.org/ 10.1007/978-3-319-47750-3_10.

Jones, C., \& Murie, A. (2006). The right to buy: Analysis and evaluation of a housing policy. Oxford: Blackwell.

Kumasi Metropolitan Assembly. (2010). Development plan for Kumasi Metropolitan Area, 2010-2013.

Lee, J., Je, H., \& Byun, J. (2011). Well-Being Index of super tall residential buildings in Korea. Building and Environment, 46(5), 1184-1194.

Liu, X., Zhang, H., \& Zhu, Q. (2012). Factor analysis of Highrise building fires reasons and fire protection measures. Procedia Engineering, 45(1), 643-648.

Mahgoub, Y., \& Abbara, B. (2011). Tall buildings legislations in Doha, Qatar. Procedia-Social and Behavioral Sciences, 36(1), 640-649.

Mao, D. R. H., \& Ong, M. E. H. (2016). High-rise residential resuscitation: Scaling the challenge. Canadian Medical Association Journal, 188(6), 399-400.

Mason, M. (2010). Sample size and saturation in Ph.D. studies using qualitative interviews. Forum: Qualitative Social Research, 11(3) [Article No. 8].

Pacione, M. (2009). Urban geography: A global perspective (3rd ed.). London: Routledge.

Parker, M. (2014). Skyscrapers: The city and the megacity. Theory, Culture and Society, 31(7-8), 267-271.

Resch, E., Bohne, R.A., Kvamsdal, T., \& Lohne, J. (2016). Impact of urban density and building height on energy use in cities. Energy Procedia, 96, 800-814. https://doi.org/10. 1016/j.egypro.2016.09.142.

Scott, P. (2017). Grenfell death toll pushes fire-related fatalities to highest level in a decade. In The telegraph. Retrieved from http://www.telegraph.co.uk/news/2017/11/09/grenfelldeath-toll-pushes-fire-related-fatalities-highest-level/.

Short, M. (2007). Assessing the impact of proposals for tall buildings on the built heritage: England's regional cities in the 21st century. Progress in Planning, 68(1), 97-199. 
Tavernor, R. (2007). Visual and cultural sustainability: The impact of tall buildings on London. Landscape and Urban Planning, 83(1), 2-12.

Turkington, R., Van Kempen, R. \& Wassenberg, F. (Eds.). (2004). High-rise housing in Europe: Current trends and future prospects. Delft: Delft University Press.

United Nations. (2014). World urbanization prospects 2014: Highlights. New York: United Nations Publications.

Wener, R., \& Comalt, H. (2006). Environmental psychology and sustainability in high-rise structures. Technology in Society, 28(1), 157-167.
Wong, G. K. M. (2004). Vertical Cities as a solution for land scarcity: the tallest public housing development in Singapore. Urban Design International, 9(1), 17-30.

Wong, J. F. (2010). Factors affecting open building implementation in high density mass housing design in Hong Kong. Habitat International, 34(2), 174-182.

Yuen, B. (2005). Romancing the high-rise in Singapore. Cities, 22(1), 3-13.

Yuen, B., et al. (2006). High-rise living in Singapore Public Housing. Urban Studies, 43(3), 583-600. 